\title{
Transesterificação do Óleo de Frango Empregando Diferentes Catalisadores
}

\section{Transesterification Oil Chicken Using Different Catalysts}

\author{
Willian Secco ${ }^{1}$; Camila da Silva2; Jamal Awadallak ${ }^{3}$; Edson Antonio da Silva ${ }^{4}$
}

\section{Resumo}

O objetivo deste trabalho foi avaliar alguns catalisadores na produção de ésteres a partir do óleo de frango bruto e óleo de frango pré-tratado (neutralizado por solução alcalina). Foram avaliados os catalisadores: Amberlyst-15, Aberlite IR-120, KSF, ZnO, CaO e metanol como álcool reagente. Nos testes preliminares foram realizados ensaios nas seguintes condições reacionais: $60^{\circ} \mathrm{C}$ e $80^{\circ} \mathrm{C}$, com $5 \%$ de catalisador em relação à massa de óleo, tempo de reação de 5 horas e razão molar álcool:óleo de 9:1.O catalisador que apresentou melhores conversões, em torno de 77\% em ésteres, foi o óxido de cálcio $(\mathrm{CaO})$. Por meio de um planejamento fatorial 23 foram realizados novos testes utilizando o óxido de Cálcio. As variáveis avaliadas no planejamento foram a temperatura, razão molar álcool:óleo, e percentagem mássica de catalisador. As maiores conversões obtidas foram de 79,8\% e 83\% para os óleos bruto e pré-tratado respectivamente, nas condições de $90^{\circ} \mathrm{C}$ de temperatura, razão molar álcool:óleo de $6: 1$ e $4 \%$ em massa de catalisador.

Palavras-chave: Transesterificação. Óleo de frango. Catalisadores. Heterogêneos.

\begin{abstract}
The aim of this study was to evaluate some catalysts in the production of esters from crude chicken and chicken oil pre-treated (neutralized by alkaline solution) oil. The catalysts were evaluated: Amberlyst-15, IR-120 Aberlite, $\mathrm{KSF}, \mathrm{ZnO}, \mathrm{CaO}$ and methanol as the reactant alcohol. The reactions took place starting at $60^{\circ} \mathrm{C}$ and $80^{\circ} \mathrm{C}, 5 \%$ catalyst relative to the mass of oil, reaction time 5 hours and molar ratio alcohol:Oil 9:1. The catalyst showed the best conversions, approximately $77 \%$ of esters, was calcium oxide $(\mathrm{CaO})$. Then new tests with $\mathrm{CaO}$ catalyst were developed. By means of a 23 factorial design were evaluated three important variables in the transesterification reaction temperature, molar ratio alcohol:oil and percentage by weight of catalyst. The highest conversions were obtained of $79.8 \%$ and $83 \%$ for crude oils and pre-treated, respectively, under the conditions of temperature $90^{\circ} \mathrm{C}$, molar ratio alcohol:oil $6: 1$ and $4 \%$ by weight of the catalyst.
\end{abstract}

Keywords: Transesterification. Chicken oil. Catalysts. Heterogeneous.

Mestre em Bioenergia, Universidade Estadual do Oeste do Paraná; williansecco@yahoo.com.br

Docente do Departamento de Engenharia de Alimentos da Universidade Estadual de Maringá - DAL-UEM; camiladasilva.eq@gmail.com

3 Doutorando em Engenharia Química, Universidade Estadual de Maringá; awadallak@hotmail.com

4 Docente do Departamento de Engenharia Química da Universidade Estadual do Oeste do Paraná - DEQ UNIOESTE; edsondeq@ hotmail.com 


\section{Introdução}

A relevância da indústria de biodiesel para o Brasil e demais países reside em grande parte na vantagem ambiental. O uso desse biocombustível em substituição ao diesel fóssil reduz acentuadamente as emissões de poluentes, atingindo $98 \%$ de redução de enxofre, $30 \%$ de aromáticos e $50 \%$ de material particulado e, no mínimo, 78\% de gases do efeito estufa. O biodiesel pode ser misturado ao diesel mineral em quaisquer proporções, e o ganho ambiental está diretamente associado ao aumento da sua proporção nas misturas (SCROCCARO, 2009).

Vários estudos relatam o uso de diferentes tipos de óleo de origem vegetal, animal, e demais materiais graxos para a produção de biodiesel. No entanto, existe uma grande discussão sobre quais matérias-primas estariam disponíveis e seriam as mais adequadas para a produção de biodiesel, uma vez que algumas fontes podem direcionar a produção para oleaginosas de importante aplicação alimentícia. Um dos maiores desafios que os combustíveis renováveis enfrentam é a questão da disponibilidade de matérias-primas capazes de atender às expectativas dos programas energéticos sem impactar a produção de alimentos (SUAREZ et al., 2009).

Por outro lado, a indústria de biodiesel encontra alternativas adicionais de matéria-prima: materiais graxos residuais, tanto de origem doméstica, quanto industrial; assim, surgem para a produção de biodiesel, as graxas e óleos, oriundos, principalmente do abate de gado, aves e suínos. Essas gorduras são vantajosas por representarem equilíbrio entre a produção de alimentos e energia, e apresentam, ainda, maior competitividade econômica na sua produção, uma vez que no Brasil sobram por ano, cerca de 500 mil toneladas de gorduras provenientes do abate de animais. Destaca-se que grande parte dessas gorduras não tem aplicação comercial, gerando um enorme volume de passivo ambiental para os frigoríficos que a produzem (SUAREZ et al., 2009).

Dados da UBA, União Brasileira de Avicultura (2011), o Brasil figura entre os maiores produtores mundiais de frango e o estado do Paraná o maior responsável por essa potencialidade.

A produção de biodiesel com matérias-primas de baixo custo tais como gorduras animais, podem representar uma interessante viabilidade econômica. A gordura de frango é uma matériaprima de baixo custo. No entanto, este óleo frequentemente contém quantidades significativas de ácidos graxos livres, o que pode levar a formação de sabões; sendo recomendado para esses casos, o abaixamento da acidez para níveis desejados, (abaixo de 1\%), utilizando um catalisador ácido antes da transesterificação (ALPTEKIN; CANAKCI, 2010).

Os ácidos e bases minerais, enzimas e bases não-iônicas representam os catalisadores mais empregados nas reações de transesterificação (principal processo de produção de biodiesel). Entretanto, a catálise homogênea ainda prevalece como a rota tecnológica mais comumente empregada pela indústria de biodiesel por possuir maior rapidez, eficiência e simplicidade em seu processo (RAMOS et al., 2003).

Por outro lado, a catálise heterogênea apresentase como uma ótima alternativa, principalmente pelas vantagens econômicas, químicas e de processo. Ao contrário do que ocorre na catálise homogênea, a catálise heterogênea requer menos etapas, a separação da glicerina ocorre mais facilmente, além de gerar uma glicerina mais pura e menos contaminada (SOLDI et al.,2007).

MOREIRA (2009) avaliou a transesterificação básica com $(\mathrm{NaOH})$ e rota metílica, utilizando óleo de frango, testanto a influência de vários parâmetros como concentração de catalisador, razão molar metanol:óleo, tempo e temperatura de reação. As melhores condições encontradas foram 1\% de catalisador, 6:1 para a razão molar álcool:óleo e transesterificação a $30{ }^{\circ} \mathrm{C}$ durante 90 minutos. O autor concluiu que é possível a produção de biodiesel empregando esse óleo destacando o fato de que essa reação ocorreu à baixa temperatura. 
Existem vários tipos de catalisadores com potencial para serem utilizados na reação de transesterificação que ainda não foram avaliados.

O objetivo principal deste trabalho foi avaliar 7 catalisadores sólidos, dentre eles: as resinas Amberlyst-15 e Amberlite-IR-120; argilas KSF e Bentonita Milbond-TX; e os óxidos $\mathrm{CaO}, \mathrm{O}_{2} \mathrm{~V}_{5}$ e $\mathrm{ZnO}$ com a finalidade de produzir ésteres metílicos pela reação de transesterificação do óleo de frango.

\section{Materiais e Métodos}

\section{Materiais utilizados}

A matéria-prima empregada para a realização deste trabalho foi o óleo de frango, produto resultante dos tecidos adiposos das aves. O gordura das aves é extraída por prensagem ou solvente após cocção, centrifugada e filtrada. Esse óleo foi fornecido pela Folem-Indústria eComércio LTDA, empresa doramo de nutrição animal que produz farinha e óleo, situada na cidade de Enéas Marques/PR. Os catalisadores avaliados nas reações de transesterificação foram: Resina Amberlyst ${ }^{\circledR}$ 15, (Sigma-Aldrich); Resina Amberlite ${ }^{\circledR}$ IR-120, (Sigma-Aldrich); Argilas KSF, (Sigma-Aldrich); Argila Milbond-TX, (Pfizer); Óxidos: $\mathrm{ZnO}, \mathrm{CaO}$ e $\mathrm{O}_{5} \mathrm{~V}_{2}$, (Vetec).

\section{Pré-tratamento do óleo (Neutralização descontínua)}

Com o objetivo de comparar o comportamento de um óleo menos impuro para a produção de biodiesel perante a reação de transesterificação em presença de catalisadores sólidos, realizou-se o prétratamento, conforme ilustrado na Figura 1:

Figura 1: Fluxograma de pré-tratamento do óleo bruto de frango.

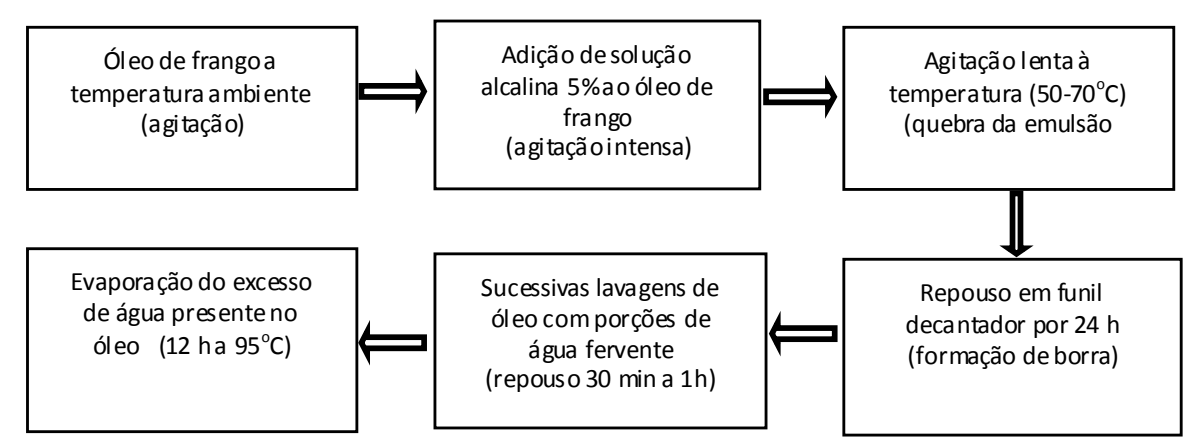

Fonte: o próprio autor

\section{O reator experimental}

As reações foram conduzidas em reator de vidro com capacidade de $500 \mathrm{~mL}$, (balão de três bocas), acoplado a um condensador. Tal reator permaneceu imerso em banho de óleo. Esse sistema estava apoiado sobre chapa aquecedora com agitação magnética constante. $\mathrm{O}$ sistema dispunha ainda de termômetro de mercúrio com faixa de temperatura entre $-10^{\circ} \mathrm{C}$ a $150^{\circ} \mathrm{C}$. Ao fim da reação a amostra foi vertida para balão de decantação, aonde a fase glicerínica e o catalisador decantavam lentamente em direção ao fundo do balão. Após 72 horas, (tempo relativamente suficiente para a decantação da glicerina e do catalisador), coletou-se a parte superior da amostra e, em seguida, a amostra permaneceu em estufa a $90^{\circ} \mathrm{C}$ para evaporação do metanol não reagido. Em seguida a amostra foi centrifugada por diversas vezes para precipitar resíduos glicerínicos e traços de catalisador. A parte superior da amostra 
foi coletada com micropipeta e enviada para análise do teor de éster conforme Norma 14103 do Comitê Europeu para padronizações.

\section{Avaliação das condições experimentais}

\section{A seleção dos catalisadores para a produção de ésteres}

Testes preliminares foram realizados para selecionar um catalisador que apresentasse maior potencial na produção de biodiesel. As condições eleitas foram aquelas que tradicionalmente são encontradas na literatura, sendo nas temperaturas de $60^{\circ} \mathrm{C}$ e $80 \mathrm{C}^{\circ}$, razão molar álcool:óleo de 9:1, porcentagem de catalisador em relação a massa de óleo de 5\%, bem como, tempo de reação de 5 horas.

\section{Preparo dos catalisadores}

Os catalisadores Amberlyst-15, AmberliteIR-120; KSF, Bentonita Milbond-TX; e $\mathrm{O}_{2} \mathrm{~V}_{5}$ foram utilizados sem nenhum tipo de tratamento. Os catalisadores $(\mathrm{CaO})$ e $(\mathrm{ZnO})$ foram previamente ativados, (calcinados em mufla a $600^{\circ} \mathrm{C}$ ) para eliminar materiais indesejáveis: (voláteis, íons instáveis, etc.) que pudesse contribuir com "massa falsa" de catalisador bem como, inativando e/ou inibindo os efeitos catalíticos desses óxidos.

\section{O Delineamento dos experimentos}

A partir dos resultados obtidos nos testes preliminares foi selecionado o catalisador que apresentou os melhores rendimentos em teores de éster - o óxido de cálcio $(\mathrm{CaO})$ - e, a partir disso, novos testes foram realizados por meio de um planejamento experimental.

Empregou-se uma ferramenta que traduzisse eficientemente as melhores condições reacionais, optando-se pelo Delineamento Composto Central Rotacional (DCCR) em fatorial $\left(2^{3}\right)$. Três importantes variáveis da reação de transesterificação foram investigadas: Temperatura com faixa entre $\left(40^{\circ} \mathrm{C}\right.$ e $\left.90^{\circ} \mathrm{C}\right)$, Razão molar metanol:óleo com faixa entre (6:1 e 12:1), e porcentagem mássica de catalisador em relação a massa de óleo entre (2\% e 4\%). O software Statistica 7.0 foi utilizado para posterior tratamento dos dados.

\section{Avaliação dos produtos obtidos}

Depois de produzido, os ésteres receberam purificação recomendada antes de serem injetados no cromatógrafo; com posterior determinação do percentual de éster em cada amostra. Importantes análises das características físico-químicas dos ésteres também foram determinadas.

\section{Resultados e Discussão}

Resultados da escolha do catalisador

O teor de ésteres obtidos com os diferentes catalisadores testados é apresentado na tabela $1 \mathrm{com}$ destaque importante para o desempenho dos óxidos, em especial o óxido de cálcio que foi selecionado para realizar novos experimentos e avaliar os efeitos da temperatura, razão molar metanol:óleo e percentagem mássica de catalisador utilizado.

Tabela 1: Catalisadores selecionados e seus desempenhos.

\begin{tabular}{ccc}
\hline Catalisador & $\begin{array}{c}\text { Ésteres } \\
\left(\mathbf{6 0}^{\circ} \mathbf{C}\right)\end{array}$ & $\begin{array}{c}\text { Ésteres } \\
\left(\mathbf{8 0}^{\circ} \mathbf{C}\right)\end{array}$ \\
\hline Amberlyst-15 & 4,97 & 9,12 \\
Amberlite IR-120 & 0,00 & 0,00 \\
$\mathrm{KSF}$ & 4,64 & 11,19 \\
Milbond-TX & Traços & Traços \\
$\mathrm{ZnO}$ & 29,94 & 34,16 \\
$\mathrm{CaO}$ & 76,30 & 77,45 \\
$\mathrm{O}_{5} \mathrm{~V}_{2}$ & $* \mathrm{NSF}$ & $* \mathrm{NSF}$ \\
\hline
\end{tabular}

*NSF $=$ Não houve separação de fases.

Fonte: o próprio autor 
Resultado do Planejamento Experimental

O objetivo do planejamento foi otimizar as três variáveis investigadas afim de encontrar a melhor condição de resposta do catalisador (em teor de ésteres).

A Tabela 2 apresenta a matriz do planejamento com os respectivos teores de ésteres obtidos pelo emprego do catalisador $\mathrm{CaO}$, tanto para o óleo bruto como para o óleo pré-tratado. Observa-se que o experimento 6 , realizado nas condições de $90{ }^{\circ} \mathrm{C}$ de temperatura, razão molar metanol:óleo de 6:1 e porcentagem de catalisador de $4 \%$ em relação à massa de óleo, produziu os melhores resultados: $79,80 \%$ de ésteres oriundos do óleo bruto e $83,00 \%$ de ésteres oriundos do óleo pré-tratado.

Tabela 2: Matriz do planejamento e teores de ésteres obtidos.

\begin{tabular}{cccccc}
\hline Exp & T $\left({ }^{\circ} \mathbf{C}\right)$ & R:M & $\begin{array}{c}\text { Cat. } \\
(\mathbf{\%})\end{array}$ & $\begin{array}{c}\text { Ésteres óleo } \\
\text { (bruto) }\end{array}$ & $\begin{array}{c}\text { Ésteres óleo } \\
\text { (tratado) }\end{array}$ \\
\hline 1 & 40 & $6: 1$ & 2 & 60,53 & 22,21 \\
2 & 90 & $6: 1$ & 2 & 70,70 & 24,25 \\
3 & 40 & $12: 1$ & 2 & 66,52 & 28,50 \\
4 & 90 & $12: 1$ & 2 & 52,10 & 27,20 \\
5 & 40 & $6: 1$ & 4 & 57,59 & 63,21 \\
$\mathbf{6}$ & $\mathbf{9 0}$ & $\mathbf{6 : 1}$ & $\mathbf{4}$ & $\mathbf{7 9 , 8 0}$ & $\mathbf{8 3 , 0 0}$ \\
7 & 40 & $12: 1$ & 4 & 71,21 & 60,21 \\
8 & 90 & $12: 1$ & 4 & 61,40 & 60,60 \\
9 & 65 & $9: 1$ & 3 & 69,35 & 72,11 \\
10 & 65 & $9: 1$ & 3 & 70,34 & 73,79 \\
11 & 65 & $9: 1$ & 3 & 74,00 & 74,18 \\
\hline
\end{tabular}

Fonte: o próprio autor

Partindo dos dados na Tabela 2 analisou-se o efeito de cada um dos parâmetros na produção de ésteres utilizando para isso o software Statistica 7.0.

Otimização das condições reacionais para o óleo bruto.

A Figura 2 revela a estimativa dos efeitos ao nível de 95\% de confiança. Somente as variáveis que estão do lado direito da linha vermelha são significativos.

Somenteavariável produto Temperatura*Razão molar apresentou efeito negativo sobre o sistema na faixa de dados analisada. Dessa forma, concluise que os melhores rendimentos obtidos ocorrem nos menores níveis dessas duas variáveis. 
Figura 2: Estimativa dos efeitos lineares e quadráticos das variáveis para o éster de óleo bruto.

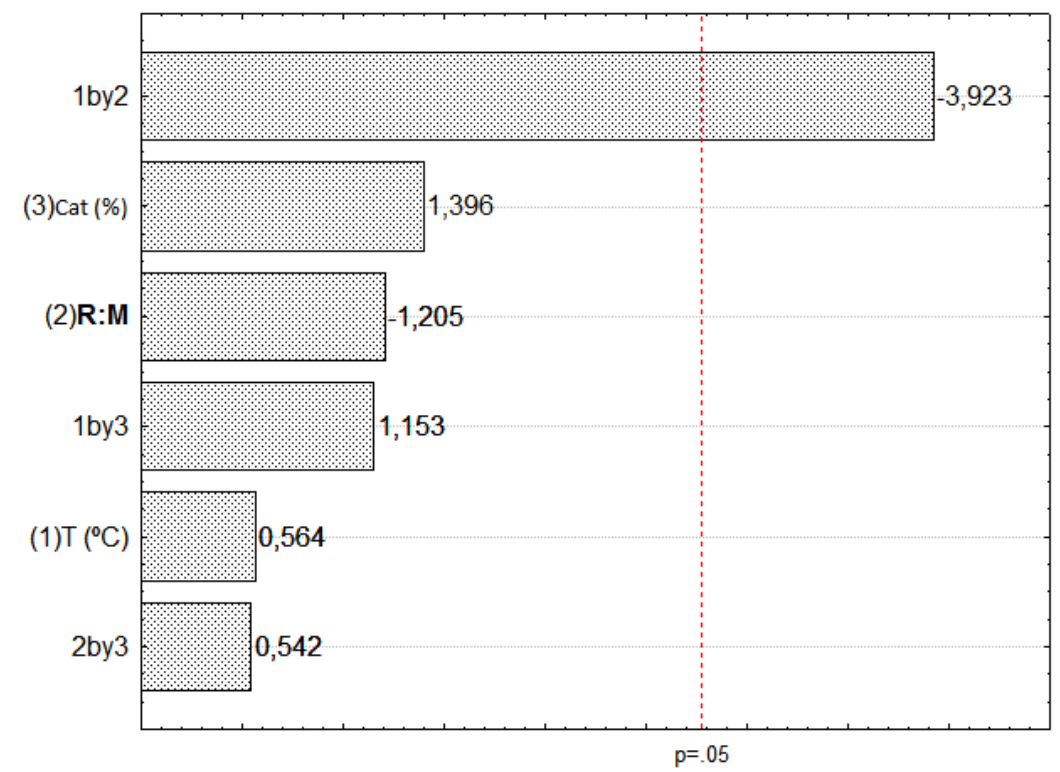

Fonte: o próprio autor

Otimização das condições reacionais para o óleo pré-tratado.

A partir dos resultados do teor de éster do óleo pré-tratado foi avaliado o efeito das variáveis por meio do gráfico de Paretto; cujos resultados são apresentados na Figura 3. Observa-se nesta figura que somente o catalisador apresenta efeito positivo sobre o sistema na faixa de dados analisada.

Figura 3: Estimativa dos efeitos lineares e quadráticos das variáveis para o éster de óleo pré-tratado.

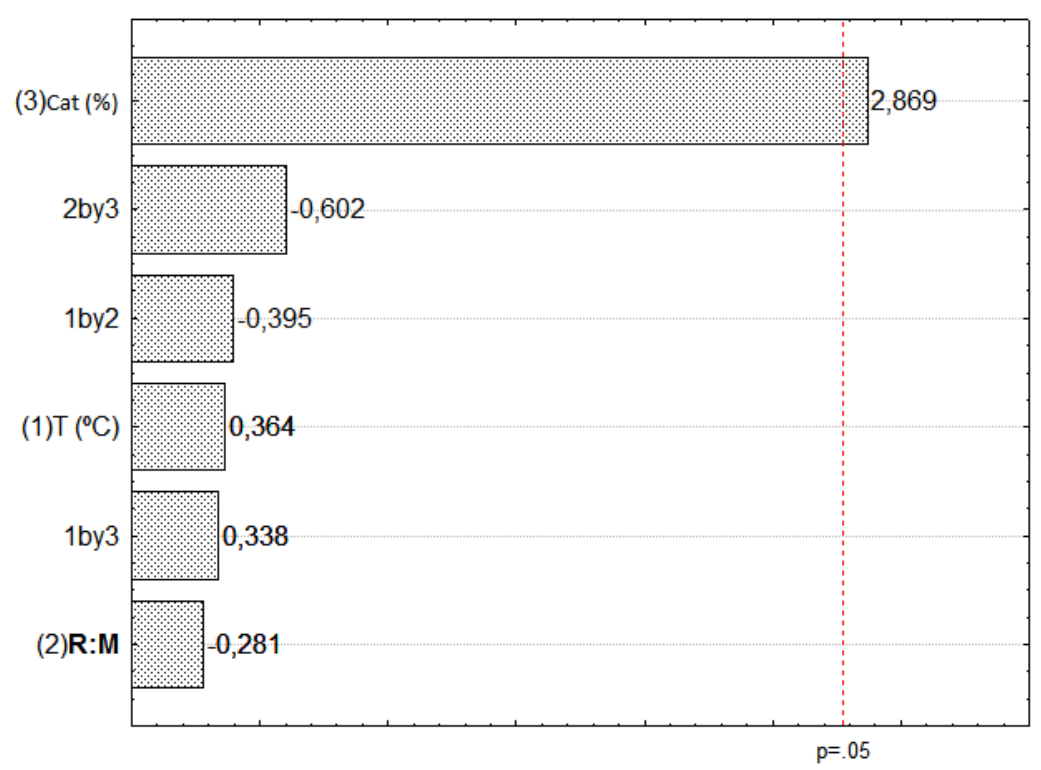

Fonte: o próprio autor 
Alptekin e Canakci (2010) avaliaram o efeito da esterificação seguida por transesterificação. Utilizaram óleo de frango como matéria-prima contendo 13,45\% de AGL. Prepararam a reação com $20 \%$ de ácido sulfúrico, razão molar metanol:óleo de 40:1 e tempo de reação de 80 minutos a $60{ }^{\circ} \mathrm{C}$ através do processo de esterificação. Após isso, a reação de transesterificação foi empregada e os resultados apresentaram um rendimento em éster metílico de $87,4 \%$.

\section{Análises físico-químicas}

A análise dos dados obtidos nos permite concluir que para os parâmetros avaliados os ésteres de óleo pré-tratado estão em maior conformidade com os parâmetros sugeridos pela ANP, tabela 3 .

Tabela 3: Especificação da ANP para biodiesel (B100), e os respectivos parâmetros avaliados dos ésteres de óleos de frango.

\begin{tabular}{|c|c|c|c|}
\hline Parâmetro & $\begin{array}{l}\text { Biodiesel } \\
\text { (ANP) }\end{array}$ & $\begin{array}{l}\text { Ésteres } \\
\text { (Bruto) }\end{array}$ & $\begin{array}{c}\text { Éster } \\
\text { (tratado) }\end{array}$ \\
\hline $\begin{array}{l}\text { Acidez (mg } \\
\mathrm{KOH} / \mathrm{g}) \text {, máx. }\end{array}$ & 0,50 & 0,39 & 0,27 \\
\hline Umidade (\%), máx. & 0,050 & --- & --- \\
\hline Iodo $\left(\mathrm{I}_{2} / 100 \mathrm{~g}\right)$ & Anotar & 81,00 & 95,00 \\
\hline $\begin{array}{l}\text { Viscosidade }\left(40^{\circ} \mathrm{C}\right) \\
\quad\left(\mathrm{mm}^{2} \cdot \mathrm{s}^{-1}\right)\end{array}$ & $3-6$ & 8,02 & 5,46 \\
\hline $\begin{array}{l}\text { Massa específica } \\
\text { Kg. } \mathrm{m}^{-3}\end{array}$ & $850-900$ & 880 & 879 \\
\hline Éster (\%) & $96,5 \%$ & 79,80 & 83,00 \\
\hline
\end{tabular}

Fonte: o próprio autor

Para o éster de óleo de frango bruto, a viscosidade ficou superior ao sugerido pela ANP. Entretanto, se considerar que quanto menor o índice de Iodo menor será as emissões de NOx, contata-se que o éster de óleo bruto apresenta uma pequena vantagem neste quesito (KNOTHE, et al., 2006).

\section{Conclusões}

Este trabalho avaliou o potencial de diferentes catalisadores sólidos para promover a reação de transesterificação do óleo de frango bruto e do óleo de frango pré-tratado. Os catalisadores avaliados foram: resinas Amberlyst-15 e Amberlite-IR-120; argilas KSF e Bentonita Milbond-TX; e os óxidos $\mathrm{CaO}, \mathrm{O}_{2} \mathrm{~V}_{5}$ e $\mathrm{ZnO}$, com destaque para o $\mathrm{CaO}$ que apresentou teores de ésteres de $76,30 \%$ a $60^{\circ} \mathrm{C}$ e de $77,45 \%$ a $80^{\circ} \mathrm{C}$. Os resultados mostraram que o prétratamento do óleo de frango não tem influência significativa na conversão de ésteres; seu efeito foi principalmente sobre as propriedades físicoquímicas dos ésteres. As máximas conversões observadas do planejamento experimental foram de $79,80 \%$ de éster para o óleo de frango bruto e, $83,00 \%$ de éster para o óleo de frango prétratado. As condições foram as seguintes: tempo 
reacional de 5 horas, temperatura de $90^{\circ} \mathrm{C}$, razão molar metanol:óleo de $6: 1$ e $4 \%$ de percentagem mássica de catalisador . O catalisador demonstrou ser a variável de maior influência nos resultados obtidos. Constata-se que dos dados observados neste trabalho é possível obter consideráveis rendimentos em ésteres utilizando matériaprima residual, (óleo de frango), e empregando um catalisador de baixo custo. É necessário, no entanto, estudos mais avançados para propiciar rendimentos em éster acima de 96,5\%. A catálise homogênea tem vantagem sob o aspecto tempo reacional, todavia, a catálise heterogênea tem como vantagens possuir processos mais simples de separação, produtos e coprodutos mais puros, reuso de materiais empregados no processo, utilização de matérias-primas de menor qualidade e, portanto, menor custo.

\section{Referências}

ALPTEKIN, E.; CANAKCI, M. Optimization of pretreatment reaction for methyl ester production from chicken fat. Fuel, London, v. 89, p. 4035-4039, 2010.

AGÊNCIA NACIONAL DE PETRÓLEO - ANP. Gás Natural e Biocombustíveis. Disponível em: <http:// www.anp.gov.br $\geq$. Acesso em: 11 maio 2012.

KNOTHE, G.; GERPEN, J. V.; KRAHL, J.; RAMOS, L. P. Manual de biodiesel. São Paulo: Edgard Blucher, 2006.

MOREIRA, A. L. V. Produção de biodiesel a partir de gordura de frango. 2009. Dissertação (Mestrado Integrado em Engenharia Química) - Universidade do Porto, Portugal.

RAMOS, L. P.; DOMINGOS, A. K.; KUCEK, K. T.; WILHELM, H. M. Biodiesel: um projeto de sustentabilidade econômica e sócio-ambiental para o Brasil. Biotecnologia: ciência e desenvolvimento, v. 31, p. 28-37, 2003.

SCROCCARO, K. I. Impregnação de heteropoliácidos em sílica para esterificação do ácido esteárico com metanol. 2009. Dissertação (Mestrado em Química) Universidade Federal do Paraná, Curitiba.
SOLDI, R. A.; OLIVEIRA, A. R. S.; RAMOS, L. P.; CESAR-OLIVEIRA, M.A.F. Estudo de catalisadores heterogêneos ácidos na metanólise do óleo de soja. In: CONGRESSO DA REDE BRASILEIRA DE TECNOLOGIA DO BIODIESEL, 2., 2007, Brasília. Anais... Brasília, 2007. p.1-6.

SUAREZ,P.A.Z.; SANTOS,A.L.F.; RODRIGUES, J. P.; ALVES, M. B. Biocombustíveis a partir de óleos e gorduras: desafios tecnológicos para viabilizá-los. Química nova, v. 32, n. 3, p. 768-775, 2009.

UNIÃO BRASILEIRA DE AVICULTURA. Relatório Anual 2010/2011. Disponível em: $<$ http://abpa-br.com.br/files/publicacoes/ abb3e2660dca967053335727b0cf74fd.pdf $>$. Acesso em: 11 maio 2012.
Recebido em 27 Novembro, 2013 - Received on November 27, 2013 Aceito em 5 Julho, 2016-Accepted on July 5, 2016 